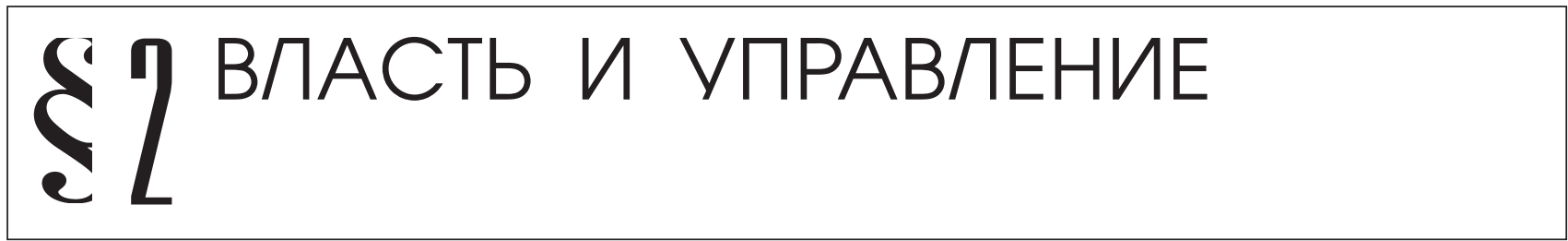

С.В. Попов

\title{
БОРЬБА РОССИЙСКИХ ПОЛИТИЧЕСКИХ ПАРТИЙ ВОКРУГ ПРИНЯТИЯ НАЛОГОВОГО И ТРУДОВОГО КОДЕКСОВ (ПО МАТЕРИАЛАМ ГОСУДАРСТВЕННОЙ ДУМЫ III СОЗЫВА)
}

\begin{abstract}
Аннотация: В статье проанализированы позиции всех фракичй и депутатских групп Государственной Думы третьего созыва по ключевым вопросам трансформации налогового законодательства и социально-трудовой сферы жизни общества. Принятие нового Налогового и Трудового кодексов вызвало неоднозначную оценку со стороны представителей различных политических сил. По мнению проправительственных и либеральных партий, содержашиеся в кодексах нормы носили прогрессивный характер и отвечали соииально-экономическим реалиям начала 2000-х г2. В то время как коммунисты со своими единомышленниками пришли к выводу, что концептуально кодексы были направлены на улучшение материального положения высокооплачиваемых граждан за счет умаления прав трудящихся.
\end{abstract}

Ключевые слова: Политология, Налоговый кодекс, Трудовой кодекс, Госдума ІІІ созыва, «Единство», ОВР, КПРФ, ЛДПР, СПС, «Яблоко»

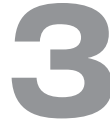

начимым для развития современно го российского общества результатом работы Государственной Думы III созыва $(2000$ - 2003 гг.) стало принятие депутатами Налогового и Трудового кодексов. Поскольку содержащиеся в них нормы меняли характер и механизмы перераспределения материальных ресурсов между различными общественными группами, то рассмотрение проектов данных кодексов сопровождалось острыми парламентскими дебатами. При этом корректировка основ налоговой системы и принципов социально-трудовых отношений происходила в новых политических условиях, когда президент и его окружение усилили свое влияние на законодательную власть ${ }^{1}$. В Госдуме III coзыва оказались представленными сразу две «партии власти» - «Единство» и «Отечество - вся Россия», которые завоевали на выборах порядка $37 \%$ голосов избирателей. Как известно, в декабре 2001 г. на базе этих политических организаций возникла Всероссийская политическая партия «Единая Россия».

Принятие Налогового кодекса РФ проходило в атмосфере многочисленных споров и столкновений между представителями различных политических

\footnotetext{
${ }^{1}$ Подробнее о дискуссиях относительно характера современной российской партийно-политической системы см.: Попов C.B. Российская власть и парламентская оппозиция в 2000-е гг. // Политика и общество. 2011. № 8. С. 86-94.
}

сил. Первая, или общая часть Налогового кодекса была одобрена депутатами Государственной Думы в трех чтениях в 1998 годуㄹ․ В ней определяются основы налогов и сборов в РФ, рамки отношений государства и налогоплательщика, но не идет речи о сущности самих специальных налогов. Им посвящена вторая, или специальная часть Налогового кодекса, которая принималась поэтапно; на рассмотрение выносились его отдельные главы, касающиеся конкретных налогов. Особый интерес вызывают позиции парламентариев при рассмотрении ими в июне - июле 2000 года проектов налога на доходы физических лиц (НДФЛ), который напрямую затрагивает всех работающих граждан.

Суть правительственной концепции налоговой реформы заключалась в переходе от прогрессивной шкалы налогообложения доходов физических лиц к единой, или плоской. Если до этого момента в зависимости от размера годового дохода ставка налога варьировалась от $12 \%$ до $35 \%$, то отныне предлагалось ввести единую ставку НДФЛ в размере 13\% для всех российских граждан. Вместе с тем налоговая реформа отменяла практически все налоговые льготы, которые предполагалось компенсировать системой налоговых вычетов: стандартных, социальных, про-

\footnotetext{
${ }^{2} 16$ апреля, 3 июля, 16 июля 1998 года соответственно.
} 
фессиональных. Иными словами, доходы граждан, которые шли на медицинское обслуживание, образование, содержание иждивенцев, теперь не входили в налогооблагаемую базу.

Главный аргумент, приводимый сторонниками реформы в пользу ее необходимости, заключался в том, что, по их мнению, слишком высокое налоговое бремя способствовало массовому укрытию реальных доходов; в особенности теми, кто был обязан платить налог по максимальной ставке ${ }^{3}$. Однако, можно предположить, что истинным мотивом полного уничтожения налоговой прогрессии было принципиальное несогласие властных и связанных с ними финансовых структур, представители которых обладали сверхвысокими заработками, с положением, когда распределение ресурсов в пользу наиболее нуждающихся слоев населения происходило за счет повышенного налогообложения владельцев крупных доходов.

Заранее предвидя критику со стороны оппонентов, присутствовавший на пленарных заседаниях Государственной Думы во время рассмотрения второй части Налогового кодекса заместитель министра финансов С.Д. Шаталов задался вопросом, «насколько с социальной точки зрения справедлива предлагаемая налоговая система». Он подчеркнул, что в отличие от существующей модели налогообложения, которая формально выглядит прогрессивной, но, по существу, является регрессивной в отношении высоких доходов, поскольку «богатые имеют вполне легальные возможности не платить налоги вовсе», единая ставка подоходного налога является более справедливой ${ }^{4}$.

Действительно, противники плоской шкалы налогообложения не заставили себя ждать. Так, представитель от Аграрной депутатской группы С.И. Штогрин подчеркнул, что «идеологически закон направлен на улучшение материального положения высокооплачиваемых граждан». На что председатель комитета Государственной Думы по бюджету и налогам, член депутатской группы «Регионы России» А.Д. Жуков ответил, что « $13 \%$ от большей суммы это больше, чем $13 \%$ от меньшей суммы», а значит такая система ни чуть не выгоднее для богатых, чем для бедных. В свою очередь, Г.В. Кулик от фракции «Отечество - вся Россия» полностью поддержал мнение С.И. Штогрина, отметив, что реформа существенно снижает налог для высокооплачиваемых социальных слоев ${ }^{5}$.

\footnotetext{
${ }^{3}$ Стенограмма пленарного заседания Госдумы 7 июня 2000 г. // Государственная Дума. Стенограмма заседаний. 2000 год. Весенняя Сессия. 24 мая - 9 июня. Том 5 (85). М., 2001. С. 558.

${ }^{4}$ Там же. С. 559-560.

${ }^{5}$ Там же. С. 574-576.
}

В ходе обсуждения выяснилось, что помимо правительственной концепции подоходного налога существует еще несколько проектов, подготовленных отдельными депутатами и группами парламентариев. Оказалось, что фракция «Единство» внесла поправку, предполагавшую трехступенчатую прогрессивную шкалу налогообложения (по сути, функционировавшую на тот момент времени). Но лидер фракции Б.В. Грызлов вместе со своими коллегами внезапно отозвал свои подписи и согласился с единой 13-процентной ставкой, дезавуировав тем самым свою изначальную позицию ${ }^{6}$. Столь неожиданный демарш «Единства» лишний раз свидетельствует о склонности «партий власти» к оппортунизму.

Член фракции «Отечество - вся Россия» Г.В. Боос выдвинул проект прогрессивно-регрессивной, или горбатой шкалы налогообложения, согласно которой в зависимости от дохода ставка НДФЛ колебалась от $12 \%$ (при годовом доходе менее 300 тысяч рублей) до 20\% (при доходе от 300 до 600 тысяч рублей) и $15 \%$ (свыше 600 тысяч рублей ежегодно). Отстаивая свою позицию, автор проекта подчеркивал, что государство не может не регулировать налогообложение разных социальных слоев населения. Вступая в полемику с А.Д. Жуковым, он подверг сомнению его тезис о том, что более состоятельные люди платят больше, так как платят с большей суммы. По мнению Г.В. Бооса, они должны платить «в несколько большем размере, чем это делают менее состоятельные люди». Горбатая шкала, согласно задумке авторов, должна была стимулировать легализацию налоговых выплат, поскольку обладатели сверхвысоких доходов получали своеобразное послабление по сравнению с владельцами средних доходов. Однако А.Д. Жуков заявил, что прогрессивно-регрессивная шкала налогообложения «может быть подвергнута критике с точки зрения социальной справедливости», равно как и гладкая шкала, поскольку Г.В. Боос предлагает облагать средний класс по максимальной ставке, а сверхдоходы - по более низкой ${ }^{7}$.

Наконец, сам А.Д. Жуков предложил собственный вариант взимания налога на доходы физических лиц, подразумевавший ставку в $12 \%$ для годового дохода до 120 тысяч рублей и 20\% для дохода свыше этой суммы, то есть снова вернулся к прогрессивной шкале, хотя и в несколько упрощенном виде по сравнению с существовавшей моделью. По его словам, принятие этой ставки меняло «идеологию закона», поскольку

\footnotetext{
${ }^{6}$ Там же. С. 594.

${ }^{7}$ Там же. С. 597-598.
} 


\section{Право и политика 3 (159) 2013}

она удовлетворяла «некоторым возражениям в части социальной справедливости» ${ }^{8}$.

Включившись в обсуждение, коммунисты выразили резкое неприятие правительственной концепции налога на доходы. Как ни странно, но они сослались на негативный опыт «уравнительного» подоходного налога в СССР и призвали обратиться к опыту западных государств, практикующих прогрессивную ставку. «Оказывается, надо уравнять налоги - и тех, кто живет архитяжело, и тех, кто жирует за счет награбленной у народа собственности», - восклицал Е.К. Лигачев. «Я не понимаю, для чего мы создали колоссальный аппарат с миллионной численностью - налоговую полицию, налоговую инспекцию», - продолжал депутат от КПРФ. Коммунисты призвали голосовать за поправку, внесенную законодательным собранием одного из субъектов федерации, оставлявшую прогрессивную ставку налогообложение практически в неизменном виде 9 .

Члены фракции «Яблоко» поддержали введение единой ставки налога на доходы физических лиц, хотя отмечали, что это решение было непростым, поскольку они осознавали его социально-экономическую значимость ${ }^{10}$. Тем не менее, уверенность в том, что новый порядок взимания подоходного налога приведет к легализации крупных заработков, окончательно склонила их поддержать правительственный проект. Впоследствии партия «Яблоко» предполагала снизить единую 13 -процентную ставку до $10 \%{ }^{11}$.

Фракции СПС и ЛДПР в ходе дискуссий не высказывали своего четкого мнения по поводу принципиального момента налоговой реформы, что свидетельствует об отсутствии сколько-нибудь значимых разногласий с предложенной правительством плоской шкалой налогообложения.

Судя по голосованию за отдельные поправки, принятие плоской шкалы налогообложения не было предопределено заранее. Если за поправку Бооса, предполагавшую прогрессивно-регрессивную шкалу, отдали голоса 167 человек ${ }^{12}$, а за поправку, предлагавшую оставить прогрессивную систему налогообложения с

\footnotetext{
${ }^{8}$ Там же. С. 598-599.

9 Там же. С. 601-602.

${ }^{10}$ Фракция «Яблоко» в Государственной Думе Федерального Собрания РФ. Законодательная деятельность, позиция, результаты голосования. 2000-2001. М., 2001. С. 78.

${ }^{11}$ Фракция «Яблоко» в Государственной Думе Федерального Собрания РФ. Законодательная деятельность, позиция, результаты голосования. М., 2003. С. 102.

${ }^{12}$ Стенограмма пленарного заседания Госдумы 7 июня 2000 г. Указ. соч. С. 598.
}

незначительными корректировками - 143 человека ${ }^{13}$, то поправке А.Д. Жукова не хватило несколько голосов, чтобы быть принятой $(210 \text { - 3а, } 110 \text { - Против })^{14}$. Тем не менее, большинство высказалось именно за правительственную концепцию налоговой реформы. Единая ставка НДФЛ была принята во втором и третьем чтениях 266 и 234 голосами соответственно.

Не осталась вне поля зрения политических партий и социально-трудовая сфера, по сути дела, охватывающая отношения между двумя большими социальными группами: наемными работниками и работодателями. Отдельные части советского Кодекса законов о труде, регулировавшего процессы в данной области, со временем утратили свою актуальность и не соответствовали ни нормотворческой терминологии, ни социально-экономической реальности, которая установилась вместе с переходом народного хозяйства на рыночные принципы развития. В итоге, принятие нового Трудового кодекса стало камнем преткновения между сторонниками различных подходов к реформированию социально-трудовой сферы.

На рассмотрение Государственной Думы поступило семь альтернативных проектов Трудового кодекса, подготовленных разными политическим силами. ${ }^{15}$. Однако основная борьба развернулась между сторонниками следующих вариантов Кодекса. Первый из них - это так называемый «согласованный проект», позиции которого отстаивал один из его авторов А.К. Исаев, заместитель Федерации независимых профсоюзов, член фракции ОВР. По большому счету, данный вариант Трудового кодекса являлся отражением позиции правительства и был переработанной версией проекта восьми депутатов (по количеству авторов), в разработке которого принимал активное участие все тот же Исаев, а также другие депутаты от фракций ОВР, КПРФ, «Единство» и группы «Народный депутат». Тем не менее, собственно проект восьми депутатов на пленарных заседаниях стал одним из наиболее обсуждаемых вариантов Трудового кодекса. Наконец, парламентарии от КПРФ, Агропромышленной депутатской группы и «Регионов России» последовательно боролись за положения своего варианта Трудового кодекса, который на заседаниях Государственной Думы представлял О.В. Шеин, состоявший на тот момент в депутатском объединении «Регионы России».

Представляя согласованный проект Трудового кодекса, А.К. Исаев охарактеризовал его как «ком-

\footnotetext{
13 Там же. С. 603.

14 Там же. С. 601.

15 Хроника пленарного заседания Государственной думы 5 июля 2001 года // URL: http://transcript.duma.gov.ru/node/1907/ (дата обращения -02.10.2011).
} 
промисс, который сохраняет целостность и основные права и гарантии трудящихся, а по целому ряду позиций усиливает защищенность работников в условиях рыночной экономики» ${ }^{16}$. Докладчик всячески подчеркивал преимущества нового кодекса перед действующим трудовым законодательством. По его мнению, он адекватно отражал уровень социальнотрудовых отношений, сложившихся в постсоветской России. При этом особо подчеркивался прогрессивный характер нового трудового законодательства в отношении прав наемных работников. В частности, Исаев остановился на ряде конкретных положений, содержащихся в проекте кодекса, выглядевших наиболее благоприятными для трудящихся.

Например, в проекте предполагалась установить штрафные санкции за каждый день просрочки заработной платы, повышенную оплату за сверхурочные работы, право на оплачиваемый отпуск уже через 6 месяцев со дня трудоустройства, а минимальный размер оплаты труда довести до уровня прожиточного минимума. Работникам предоставлялось право на 15-й день задержки заработной платы приостановить работу, письменно уведомив об этом работодателя, до полного погашения задолженности. Повышался уровень оплаты простоя по вине работодателя, а также при невыработке нормы по его вине. Вводилась до этого отсутствовавшая глава, регулирующая труд наемных работников у работодателя - физического лица. Категорически запрещались работа в ночное время, сверхурочная работа, привлечение к работе в выходные и праздничные дни беременных женщин и несовершеннолетних работников. Предполагалось ввести четкий перечень оснований для заключения срочного трудового договора ${ }^{17}$.

Исаев особо подчеркивал, что проект серьезно «изменяет роль профессиональных союзов». По его словам, в отличие от существовавших в то время норм трудового права, когда процедура согласования с профсоюзами целого ряда решений, затрагивающих интересы работников, не была определена, в согласованном проекте «была зафиксирована, подробнейшим образом описана процедура учета мнения профсоюзного органа». Механизм учета мнения профсоюзов подразумевал, в свою очередь, «заблаговременное ознакомление профсоюза с проектом решения руководства, возможность дать мотивированный письменный отзыв, проведение переговоров, целью которых

\footnotetext{
${ }^{16}$ Стенограмма пленарного заседания Госдумы 5 июля 2001 г. // Государственная Дума. Стенограмма заседаний. 2001 год. Весенняя Сессия. 27 июня - 11 июля. Том 19 (99). М., 2003. С. 467.

${ }^{17}$ Там же. С. 468-471.
}

должна быть выработка согласованного решения» ${ }^{18}$. Но именно то место, которое отводилось составителями согласованного проекта профсоюзам в системе социально-трудовых отношений, и стало одним из самых дискуссионных моментов в ходе парламентских дебатов, посвященных рассмотрению вариантов нового Трудового кодекса.

Основной упрек, звучавший в адрес согласованного проекта со стороны оппонентов, заключался в том, что он ставил в неравное положение крупные и малочисленные профсоюзы. Наиболее категоричны в данном случае были коммунисты, представитель которых В.А. Зорькин обратился лично к Исаеву, назвав его «могильщиком профсоюзов» ${ }^{19}$. В чем же кроется причина концептуальных разногласий между сторонниками и противниками согласованного проекта Трудового кодекса относительно профсоюзного движения?

К примеру, проект, представленный О.В. Шеиным, предусматривал, что в случае, если на предприятии существует несколько профсоюзов, то каждый из них имеет право вести переговоры с руководством о заключении коллективного договора ${ }^{20}$. В то время как согласованный проект обязывал все профсоюзные организации, существующие на предприятии, сформировать общий орган по заключению коллективного договора. Но в случае, если им не удавалось прийти к компромиссу, то правом заключения коллективного договора обладал лишь наиболее представительный профсоюз, включающий более $50 \%$ персонала 21 . Очевидно, что такой расклад был к наибольшей выгоде крупных профессиональных союзов, и тень падала именно на главного апологета согласованного проекта А.К. Исаева, так как он состоял в руководстве Федерации независимых профсоюзов, обладающей разветвленной сетью организаций на предприятиях различных отраслей. Поправка, внесенная депутатами с целью сохранить, по выражению Шеина, «демократичное право любого профсоюза на ведение переговоров по заключению коллективного договора» во втором чтении законопроекта депутатами была отклонена ${ }^{22}$.

Выступая в поддержку проекта восьми депутатов, его разработчики также коснулись проблемы малых профсоюзов. По их убеждению, принятие

\footnotetext{
${ }^{18}$ Там же. С. 471-472.

${ }^{19}$ Там же. С. 511.

${ }^{20}$ Там же. С. 493.

${ }^{21}$ Там же. С. 512.

${ }^{22}$ Стенограмма пленарного заседания Госдумы 19 декабря 2001 г. // Государственная Дума. Стенограмма заседаний. 2001 год. Осенняя сессия. 19 декабря - 27 декабря. Том 25 (105). М., 2004. С. 121.
} 


\section{Право и политика 3 (159) 2013}

согласованного кодекса было чревато ликвидацией «новых независимых профсоюзов, созданных снизу самими гражданами». При этом они отмечали, что «роль профсоюзов не ограничивается регулированием социально-трудовых отношений», поскольку они являются «основными ячейками структуры гражданского общества, без существования которых невозможно построение демократического общества в России». Поэтому тот факт, что правительство стремилось «встроить аморфную структуру ФНПР в свою вертикаль», а представители последней «с большой охотой согласились с ролью приводных ремней власти», едва ли могло свидетельствовать о прогрессивном характере нового трудового законодательства ${ }^{23}$.

Депутаты высказали свое принципиальное несогласие и по поводу прописанной в согласованном проекте роли профсоюзов непосредственно в трудовых отношениях. Так, по мнению Исаева, полномочия профсоюзов должны были ограничиваться лишь тем, что они имели возможность выразить свое мнение относительно технологического процесса, решений руководства предприятия и прочих вопросов производственно-трудового характера. В данном случае за работодателем оставалось право принять во внимание, исполнить или проигнорировать замечания членов профсоюза. А, по выражению депутата от фракции КПРФ В.Т. Сайкина, это означало, что «работники получили право просить, а работодатели имели право отказать», что было свидетельством умаления тех прав, которые имели профсоюзы по советскому трудовому законодательству ${ }^{24}$.

Разработчики «проекта восьми» подчеркивали, что они оставили в неизменном виде, а в каких-то случаях расширили права профсоюзов как представителей трудящихся. За работодателями была сохранена обязанность именно согласовывать с профсоюзными органами нормативные акты о труде, а также увольнения работников по части оснований, прежде всего при сокращении численности штата предприятия ${ }^{25}$. Об этом гласила и поправка О.Н. Смолина (Аграрная депутатская группа), которая не обязывала работодателя согласовывать некоторые решения с профсоюзами, а всего лишь допускала такую возможность. Несмотря на такой мягкий вариант предлагаемой нормы трудового законодательства

${ }^{23}$ Стенограмма пленарного заседания Госдумы 5 июля 2001 г. Указ. соч. С. 489-490.

${ }^{24}$ Там же. С. 528.

${ }^{25}$ Там же. С. 488. в отношении работодателя, поправка была отклонена $^{26}$. Аналогичные поправки вносились повторно депутатами от фракции КПРФ и членами «Яблока», но результат голосования оставался тем же.

Проект О.В. Шеина также значительно расширял деятельность профсоюзных организаций в общественно-политической жизни. Профсоюзы планировалось наделить правом законодательной инициативы, а также расширить их материальные возможности, обязав предприятия обеспечить профсоюзы средствами связи, транспортом и помещениями ${ }^{27}$. А в варианте Трудового кодекса, разработанном восемью депутатами с целью стимулирования активности трудящихся по защите своих законных прав, была введена норма, согласно которой профсоюзные представители получали неприкосновенность ${ }^{28}$. Иными словами, механизм их привлечения к дисциплинарной ответственности, а также процедура увольнения становились затрудненными для руководства организаций.

Как отмечалось выше, первоначально А.К. Исаев был одним из соавторов проекта восьми депутатов, содержавшего нормы, которые открывали работникам большие по сравнению с согласованным вариантом возможности защищать свои трудовые права. По свидетельству члена Агропромышленной депутатской группы А.В. Чекиса, до определенного времени Исаев был последовательным сторонником своего проекта, вместе с Федерацией независимых профсоюзов устраивал акции протеста против правительственного варианта Трудового кодекса, заявляя, что он «расширяет полномочия работодателя и делает декоративной роль профсоюзов». Но при рассмотрении альтернативных проектов в первом чтении появилось заключение того же А.К. Исаева, в котором уже проект восьми депутатов характеризовался неприемлемым в плане защиты интересов работников и учета реалий рыночной экономики ${ }^{29}$. Словом, за короткий отрезок времени автор законопроекта поменял свою позицию на диаметрально противоположную, что, безусловно, связано с объединительными процессами между двумя политическими организациями: «Отечество - вся Россия»и «Единство». Отныне депутаты, состоявшие во фракциях этих партий в Государственной Думе, должны были голосовать консолидировано в поддержку правительственных решений.

\footnotetext{
${ }^{26}$ Стенограмма пленарного заседания Госдумы 19 декабря 2001 г. Указ. соч. С. 108-109.

${ }^{27}$ Шеин О.В. Трудовой кодекс. Проект. Спб., 2001. С.15.

${ }^{28}$ Стенограмма пленарного заседания Госдумы 5 июля 2001 г. Указ. соч. С. 488-489.

${ }^{29}$ Там же. С. 544.
} 
Прения среди депутатов вызвал и вопрос об оплате труда. То, что согласованный проект закреплял норму о соответствии минимального размера оплаты труда уровню прожиточного минимума, депутатам показалось недостаточной мерой. Например, депутаты от фракции «Яблоко» предлагали установить MPOT на уровне тройного прожиточного минимума, поскольку, по их данным, на одного занятого в экономике работника приходится не менее одного иждивенца без источников дохода, которого содержит трудящийся ${ }^{30}$.

Депутат О.В. Шеин предложил перейти в России к почасовой системе оплаты труда. При этом предполагалась изменить саму структуру заработной платы, чтобы избежать «неравной платы за равный труд». Речь шла о недопущении ситуации, когда оклад составлял лишь 15-20\% от суммы заработной платы, а остальная часть выдавалась гражданам в виде премии. Суть предложения заключалась в том, чтобы установить долю твердого тарифа, или оклада в размере $80 \%$ от оплаты труда ${ }^{31}$. Но сторонники согласованного проекта проигнорировали данную поправку, не приняв участия в голосовании ${ }^{32}$.

Стоит отметить, что либеральные партии в целом высказались в поддержку согласованного проекта Трудового кодекса, хотя и имели собственные предложения по совершенствованию трудового законодательства. Фракция «Яблоко» отдала свои голоса в его пользу потому, что он вводил материальную ответственность работодателя за задержку заработной платы и фиксировал, что минимальный размер оплаты труда не может быть ниже прожиточного минимума ${ }^{33}$. А члены фракции СПС, поддерживая согласованный вариант, привели истинно либеральные доводы в пользу реформирования трудового законодательства. Выражая позицию всей фракции, В.В. Похмелкин подчеркнул крайне негативную роль остатков советского законодательства в сфере регулирования трудовых отношений и необходимость недопущения реставрации «социалистических» норм и правил в данной области ${ }^{34}$.

Депутат Похмелкин отметил, что «работодатель несет только одну обязанность - справедливо опла-

\footnotetext{
30 Там же. С.477.

${ }^{31}$ Там же. С. 493-494.

${ }^{32}$ Стенограмма пленарного заседания Госдумы 19 декабря 2001 г. Указ. соч. С. 174.

${ }^{33}$ Фракция «Яблоко» в Государственной Думе Федерального Собрания РФ. Законодательная деятельность, позиция, результаты голосования. 2000-2001. М., 2001. С. 53.

${ }^{34}$ Стенограмма пленарного заседания Госдумы 5 июля 2001 г. Указ. соч. С. 535.
}

чивать труд человека», и недопустимо «функцию социальной защиты людей, которые в ней нуждаются, возлагать на работодателя». Более того, по мнению членов фракции СПС, «в защите нуждается только добросовестный и профессионально подготовленный работник» ${ }^{35}$. Тем самым, по выражению В.В. Похмелкина, его партия формировала новый образ работодателя и работника, когда первый «будет исходить из принципов социального партнерства», а второй «дорожить своим местом». Притом что «полумаргинальные работники, зараженные патерналистскими настроениями», которые «цепляются за любые формы коллективного существования», должны превратиться в ответственных и независимых трудящихся ${ }^{36}$.

Позиция ЛДПР, озвученная ее бессменным лидером, была противоречива и оригинальна. С одной стороны, В.В. Жириновский признал, что функционировавший Кодекс законов о труде устарел, и депутаты должны принять новый, согласованный с правительством. В ходе обсуждения представителями фракции не было высказано веских замечаний в адрес проекта. С другой стороны, лидер ЛДПР добавлял, что в трудовом законодательстве нужна стабильность, поэтому «надо было оставить в покое царский кодекс о труде, добавить кое-что в советский период» и тогда не было бы необходимости принимать новый Трудовой кодекс ${ }^{37}$.

Наконец, фракция «Единство» полностью поддержала концепцию согласованного кодекса и заявила, что «будет голосовать консолидировано» за его принятие, поскольку «те вопросы, которые расширяют права трудящихся, нашли яркое отражение в нем» ${ }^{38}$.

В итоге, за согласованный проект Трудового кодекса в первом чтении проголосовали 277 депутатов. Практически в полном составе его поддержали депутаты от фракций «Единство», ОВР, «Яблоко», СПС, ЛДПР, а также большинство представителей «Регионов России» и «Народного депутата». Очевидно, что данный расклад политических сил в Государственной Думе предопределил прохождение законопроекта во втором и третьем чтениях. Одновременно, подавляющая часть фракции КПРФ и Агропромышленной депутатской группы в голосовании участия не приняли, вероятно, в знак несогласия

\footnotetext{
35 Там же. С. 536.

36 Там же. С. 540.

37 Там же. С. 532.

38 Там же. С. 523.
} 


\section{Право и политика 3 (159) • 2013}

с правительственной концепцией реформы ${ }^{39}$. За проект О.В. Шеина отдали голоса 189 человек. Наконец, проект восьми депутатов поддержали 150 человек ${ }^{40}$.

Таким образом, оценки согласованного с правительством проекта Трудового кодекса, положения которого разъяснял один из его авторов А.К. Исаев, разделились. Явное неприятие правительственной концепции реформирования трудового законодательства выразили коммунисты и члены Агропромышленной депутатской группы. Они поддержали альтернативные проекты, в которых, по их мнению, положение трудящихся оставалось по крайней мере на уровне действовавшего на тот момент законодательства. Несмотря на некоторые предложения, либеральные партии «Яблоко» и СПС, напротив, не увидели в Трудовом кодексе принципиальных изъянов, ухудшавших социальное положение трудящихся. Более того, представители СПС предполагали более радикальную трансформацию социально-трудовой сферы путем снижения до минимума полномочий профсоюза как действенного органа, стоящего на страже защиты прав рабочих. Члены ЛДПР, высказавшись за необходимость сохранения преемственности в трудовом законодательством, в том числе и с советским КЗоТом, одобрили правительственную концепцию кодекса. Наконец, фракции «Единство» и ОВР в полном составе поддержали концепцию согласованного кодекса, представляя его более прогрессивным, нежели действовавший на тот момент Кодекс законов о труде, в особенности в части социальных и трудовых прав граждан.

Примечательно, что представители «партий власти» до определенного момента стремились демонстрировать свою независимость от правительства в вопросах налогового и трудового законодательства. Так, депутаты фракции «Единство» изначально защищали прогрессивную систему налогообложения. А у членов фракции ОВР возникли разногласия с правительственной концепцией реформирования трудового законодательства, поскольку они считали предлагаемые нормы умалением социально-трудовых прав населения. Однако постепенно «партии власти» стали поддерживать правительственную позицию, доказав, что руководствуются не идейными принципами, а установками свыше. Особо отчетливо это проявилось при окончательном обсуждении проектов все тех же Налогового и Трудового

\footnotetext{
${ }^{39}$ Информационно-аналитические материалы Государственной Думы. Анализ голосований. // URL: http://iam.duma.gov.ru/node/1/4083 (Дата обращения - 02.10.2011).

${ }^{40}$ Стенограмма пленарного заседания Госдумы 5 июля 2001 г.
} Указ. соч. С. 560. кодексов, когда депутаты фракций «Единство»и «Отечество - вся Россия» внезапно меняли свою точку зрения на противоположную, принимая варианты законопроектов, которые были согласованы с правительством.

Реформы налогового и трудового законодательства нашли поддержку и в среде либеральных партий. СПС поддержала их безоговорочно, в то время как члены «Яблока» высказывали некоторые предложения, в целом не менявшие концепцию Налогового и Трудового кодексов. Либеральнодемократическая партия России также выступила в роли сторонницы правительственного курса преобразований. Вероятно, в понимании этих партий, правительственные варианты кодексов вполне отвечали потребностям времени, а также социальной составляющей их программ.

Наконец, депутаты фракции КПРФ в Госдуме, а также блокирующаяся с ними Аграрная депутатская группа, выступили в качестве последовательной оппозиции налоговой реформе и принятию нового Трудового кодекса, восприняв трансформацию основ социальной политики как покушение на те справедливые, с их точки зрения, механизмы распределения ресурсов, которые остались еще со времени существования советской общественной системы.

В итоге, принятие новых кодексов явилось составной частью социально-политических и экономических преобразований, инициированных властью с избранием В.В. Путина на президентский пост. Партийные баталии, сопровождавшие обсуждение данных законопроектов в парламенте, свидетельствуют о наличии в обществе социальных групп, несогласных с курсом правящей элиты. Однако построение так называемой «исполнительной вертикали» привело к постепенной монополизации Кремлем партийно-политического пространства и отторжению властью альтернативных программ трансформации отдельных сфер общественной жизни, которые, в частности, выносились на рассмотрение Государственной Думы третьего созыва депутатами различных фракций.

\section{Библиография}

1. Информационно-аналитические материалы Государственной Думы. Анализ голосований // URL: http://iam.duma.gov.ru/node/1/4083 (Дата обращения - 02.10.2011).

2. Попов С.В. Российская власть и парламентская оппозиция в 2000-е гг. // Политика и общество. 2011. № 8. С. 86-94. 
Власть и управление

3. Стенограмма пленарного заседания Госдумы 7 июня 2000 г. // Государственная Дума. Стенограмма заседаний. 2000 год. Весенняя Сессия. 24 мая - 9 июня. Том 5 (85). М., 2001.

4. Стенограмма пленарного заседания Госдумы 5 июля 2001 г. // Государственная Дума. Стенограмма заседаний. 2001 год. Весенняя Сессия. 27 июня - 11 июля. Том 19 (99).

5. Стенограмма пленарного заседания Госдумы 19 декабря 2001 г. // Государственная Дума. Стенограмма заседаний. 2001 год. Осенняя сессия. 19 декабря - 27 декабря. Том 25 (105).

6. Фракция «Яблоко»в Государственной Думе Федерального Собрания РФ. Законодательная деятельность, позиция, результаты голосования. 2000-2001. М., 2001.
7. Фракция «Яблоко»в Государственной Думе Федерального Собрания РФ. Законодательная деятельность, позиция, результаты голосования. M., 2003.

8. Хроника пленарного заседания Государственной думы 5 июля 2001 года // URL: http://transcript.duma. gov.ru/node/1907/ (дата обращения - 02.10.2011).

9. Шеин О.В. Трудовой кодекс. Проект. Спб., 2001.

\section{References (transliteration):}

1. Popov S.V. Rossiyskaya vlast' i parlamentskaya oppozitsiya v 2000-e gg. // Politika i obshchestvo. 2011. № 8. S. 8694 .

2. Shein O.V. Trudovoy kodeks. Proekt. Spb., 2001. 